INTENSIF, Vol.3 No.2 August 2019

ISSN: 2580-409X (Print) / 2549-6824 (Online)

DOI: https://doi.org/10.29407/intensif.v3i2.12769

\title{
Pemodelan Data Warehouse Distribusi Produk di PT. X
}

Data Warehouse Modeling for Product Distribution at PT. X

\author{
Diterima: \\ 5 Maret 2019 \\ Revisi: \\ 18 Juni 2019 \\ Terbit: \\ 1 Juli 2019
}

\author{
${ }^{1}$ Rani Susanto, ${ }^{2}$ Tati Harihayati M \\ ${ }^{1,2}$ Teknik Informatika, Universitas Komputer Indonesia \\ ${ }^{1,2}$ Bandaung, Indonesia \\ E-mail: ${ }^{1}$ rani.susanto@email.unikom.ac.id, \\ ²tati.harihayati@email.unikom.ac.id
}

\begin{abstract}
Abstrak-Tujuan dari penelitian ini adalah untuk memberikan gambaran umum dari Kepala Distribusi PT. X untuk mendukung kegiatan pemantauan distribusi produk dalam hal jumlah produk yang akan didistribusikan ke setiap kantor cabang sesuai kebutuhan. Masalah yang terjadi adalah banyaknya jumlah dan keragaman produk yang dibutuhkan di mana setiap kantor cabang berada berjauhan, menyebabkan perusahaan kesulitan dalam mengumpulkan data produk yang berfungsi untuk proses pemantauan. Solusi untuk masalah ini adalah diperlukan model yang dapat digunakan untuk mengumpulkan semua data yang diperlukan untuk memantau distribusi produk menggunakan metode Data warehouse. Metode ini digunakan untuk mengumpulkan beragam data ke dalam area penyimpanan sehingga pengguna dapat dengan cepat menganalisis data yang dibutuhkan. OLTP adalah bagian dari Gudang Data, yang merupakan tahap awal pemodelan sumber data, kemudian dengan proses ETL, yang merupakan dasar untuk pemodelan skema gudang data. Jadi, model ini dapat digunakan sebagai referensi untuk menghasilkan informasi yang bermanfaat bagi pihak manajerial PT. X dalam penelitian selanjutnya.
\end{abstract}

Kata Kunci-Data Warehouse, OLTP, ETL, Monitoring

Abstract - The purpose of this study is to provide an overview of the Head of Distribution of PT. X to support product distribution monitoring activities in terms of the number of products to be distributed to each branch office as needed. The problem that occurs is the large number and diversity of products required where each branch office is located far apart, cause the company difficulty in collecting product data that functions for the monitoring process. The solution to this problem is there needs a model that can be used to collect all the necessary data for monitoring product distribution using the Data warehouse method. This method is used to collect diverse data into a storage area so that users can quickly analyze the data needed. OLTP is part of the Data Warehouse, which is the initial stage of modeling data sources, then with ETL processes, which are the basis for modeling data warehouse schemes. So, this model can be used as a reference to produce useful information for managerial parties $P T$. $X$ in the next study.

Keywords-Data Warehouse, OLTP, ETL, Monitoring 


\section{PENDAHULUAN}

PT. X adalah perusahaan yang bergerak dalam distribusi produk dan memiliki 3 kantor cabang yang terletak di Bandung, Yogyakarta dan Surabaya. Masalah yang terjadi yaitu banyaknya jumlah dan keberagaman produk yang dibutuhkan oleh setiap kantor cabang, dimana setiap kantor cabang letaknya berjauhan sehingga mengakibatkan perusahaan khususnya Kepala Distribusi mengalami kesulitan dalam mengoleksi data produk yang akan digunakan untuk proses monitoring. Kepala Distribusi mengalami kesulitan dalam menentukan keputusan jumlah dan jenis produk yang harus didistribusikan ke setiap kantor cabang karena keberadaan data produk yang terpisah dan memiliki tipe yang berbeda. Metode data warehouse merupakan solusi yang digunakan pada penelitian ini. Metode Data Warehouse digunakan untuk menyatukan data yang beragam ke dalam sebuah tempat penyimpanan dimana pengguna dapat dengan mudah menjalankan query, menghasilkan laporan dan melakukan analisis[1]. Data warehouse, menjadikan data perusahaan yang tersebar menjadi terintegrasi dan ringkas untuk membantu pengguna menganalisis data yang ada untuk pengambilan keputusan yang bersifat strategis secara cepat dan tepat [2]. DK Widyawati [3] dalam penelitiannya menyatakan bahwa dengan menerapkan data warehouse pemimpin perusahaan akan dapat merencanakan produk dengan mudah sesuai dengan wilayah pemasarannya. Menurut J Christian [4], struktur data warehouse berguna untuk mempermudah mengintegrasikan kebutuhan data agar level manajerial dapat lebih mudah mendapatkan keputusan. Menurut F.Y. Al Irsyadi [12] dalam penelitiannya menyatakan bahwa data warehouse yang dibangun dapat menampilkan informasi yang lebih rinci dari setiap dimensi sesuai dengan aturan hirarki field setiap dimensi. Penerapan data warehouse sangat membantu dunia bisnis saat ini, dimana biasanya membutuhkan analisis yang cepat dan tepat untuk memperoses data menjadi informasi penting yang berguna bagi perusahaan dalam mengambil keputusan $[14,15]$. Dari permasalahan tersebut maka perlu dibangun sebuah model data warehouse yang dapat menjadi acuan untuk menghasilkan informasi yang berguna bagi level manajerial PT. X dan diawali dengan pembangunan skema OLTP sebagai sumber data transaksional yang digunakan dan dilanjutkan dengan proses ETL untuk mendapatkan skema data warehouse sebagai model terbaik yang dibutuhkan sebagai wadah untuk menampung data yang awalnya terpisah menjadi lebih mudah dalam pengelolaannya. 
INTENSIF, Vol.3 No.2 August 2019

ISSN: 2580-409X (Print) / 2549-6824 (Online)

DOI: https://doi.org/10.29407/intensif.v3i2.12769

\section{METODE PENELITIAN}

Penelitian ini menggunakan pendekatan kuantitatif dengan menggunakan metode deskriptif yang melakukan studi banding untuk membandingkan fenomena yang telah ditemukan[5]. Tahapan pertama dari penelitian ini yaitu melakukan observasi dan pengumpulan data terhadap permasalahan yang akan diteliti berdasarkan teori yang digunakan. Tahapan kedua yaitu melakukan analisis sumber data yang diperlukan oleh penelitian ini lalu merancang sebuah skema OLTP (Online Transaction Processing). Skema OLTP ini akan menjadi source yang berasal dari data operasional [6]. Source OLTP ini berasal dari format Ms. Excel yang diubah kedalam sebuah skema dan sudah melalui tahapan normalisasi tabel. Normalisasi adalah peralatan yang digunakan untuk mengelompokkan data menjadi tabel-tabel yang menunjukan entitas dan relasinya [7]. Tahapan selanjutnya yaitu Analisis Informasi Strategis yang menjadi acuan kebutuhan perusahaan yang akan diteliti.

Tahapan keempat dari penelitian ini yaitu melakukan analisis data warehouse yang dimulai dengan tahapan Data Staging yaitu tahapan menyediakan tempat dan area dengan sekumpulan fungsi untuk membersihkan, merubah, mengkombinasikan, menggandakan dan menyiapkan sumber data untuk penyimpanan tanpa mengubah nilai dari data tersebut [8]. Proses yang terjadi di data staging tersebut yaitu proses ETL (Extract, Transform, Load). Setelah melakukan tahapan tersebut, tahapan selanjutnya yaitu membentuk sebuah skema data warehouse yang merupakan model terbaik yang dihasilkan untuk pembangunan data warehouse [9]. Menurut Patel [13] dalam penelitiannya menyatakan bahwa hal yang penting dalam proses pembangunan data warehouse adalah proses modelling. Pemodelan data warehouse ada dua jenis yaitu Skema Bintang (star schema) dan Skema Bola Salju (Snowflake schema) [10]. Skema yang digunakan pada penelitian ini yaitu Snowflake schema karena merupakan perbaikan dari star schema yaitu terdapat beberapa hierarki yang ada di tabel dimensi yang didekomposisi menjadi tabel yang lebih kecil. Artinya sebuah tabel fakta bisa terkoneksi dengan berbagai tabel dimensi atau sebaliknya, sehingga dapat meminimalkan terjadinya redundancy data dan sumber data yang dapat diolah untuk menjadi informasi yang dibutuhkan menjadi lebih banyak dan lebih rinci [16]. 


\section{HASIL DAN PEMBAHASAN}

PSumber data yang digunakan pada penelitian ini berasal dari empat jenis laporan yaitu : laporan stok produk, laporan Supplier, laporan transaksi dan laporan distribusi produk. Laporan tersebut berbentuk fisik dan berisi data operasional dengan banyak data yang tidak tersusun dan memiliki nilai ganda. Semua Laporan tersebut melalui tahapan normalisasi sehingga menghasilkan 12 jenis tabel yaitu tabel produk, pengadaan, detail pengadaan, supplier, persediaan, cabang, persediaan cabang, pengiriman, detail pengiriman, konsumen, penjualan dan detail penjualan. Seluruh tabel yang telah dihasilkan dibentuk ke dalam sebuah Skema Relasi OLTP. Skema Relasi OLTP terdapat pada gambar 1.

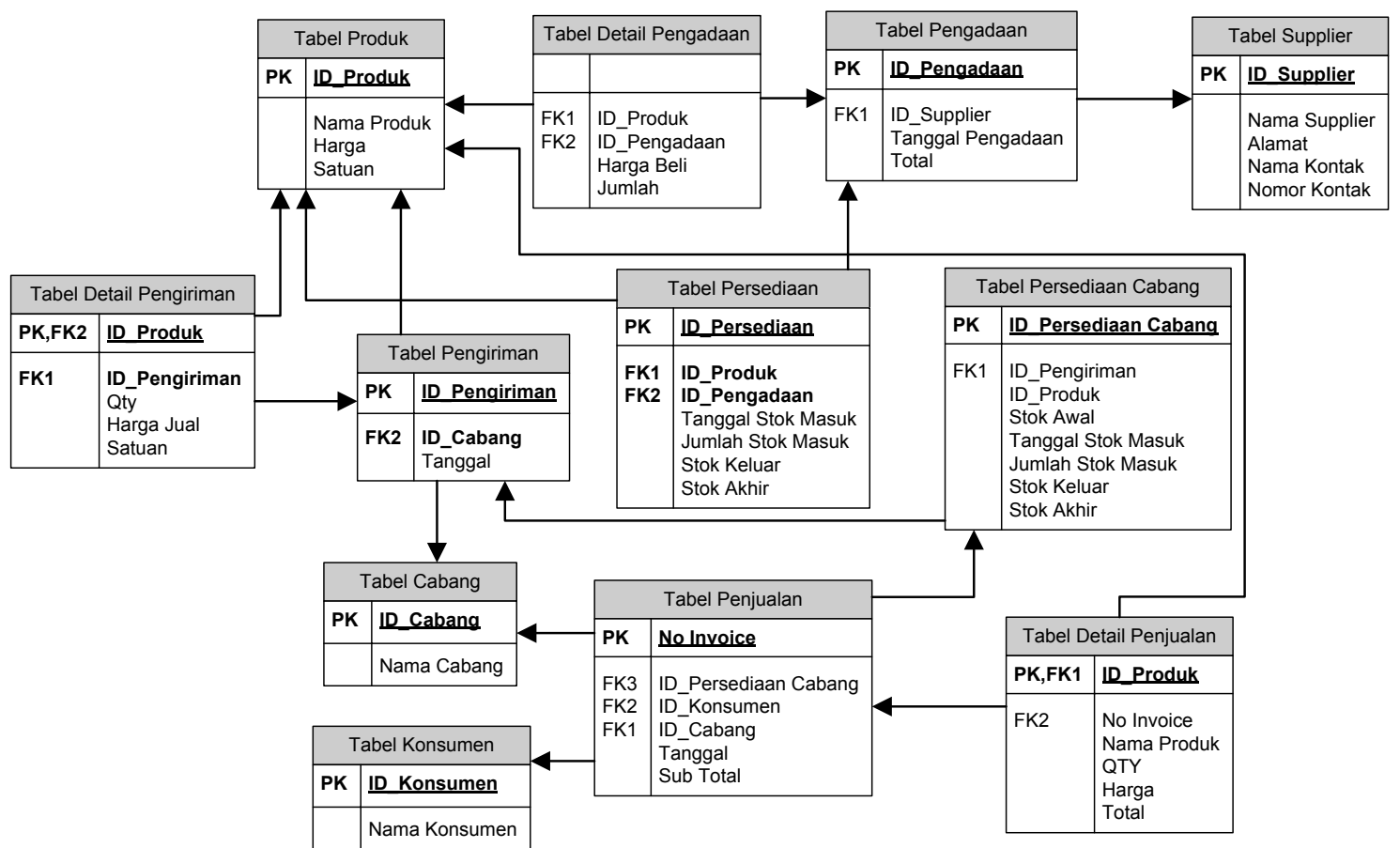

Gambar 1. SKEMA RELASI OLTP

Berdasarkan permasalahan yang diteliti didapatkan kebutuhan informasi strategis yang dibutuhkan perusahaan yaitu kebutuhan yang berkaitan dengan stok produk,penjualan serta distribusi produk ke setiap kantor cabang. Tahapan selanjutnya pada penelitian ini yaitu analisis data staging yaitu tahapan menyediakan tempat dan area untuk kegiatan ETL [8-9]. 
INTENSIF, Vol.3 No.2 August 2019

ISSN: 2580-409X (Print) / 2549-6824 (Online)

DOI: https://doi.org/10.29407/intensif.v3i2.12769

\section{A. Extract}

Extract yaitu proses memilih dan mengambil data dari satu atau beberapa sumber dan membaca/mengakses data yang dipilih tersebut [11]. Tabel hasil extract terdapat pada Tabel 1.

Tabel 1. TABEL EXTRACT

\begin{tabular}{|c|c|}
\hline Nama Tabel & Field \\
\hline \multirow[t]{2}{*}{ Tabel Produk } & ID_Produk \\
\hline & Nama Produk \\
\hline \multirow[t]{2}{*}{ Tabel Cabang } & ID_Cabang \\
\hline & Nama_Cabang \\
\hline \multirow[t]{2}{*}{ Tabel Konsumen } & ID_Konsumen \\
\hline & Nama Konsumen \\
\hline \multirow[t]{2}{*}{ Tabel Supplier } & ID_Supplier \\
\hline & Nama Supplier \\
\hline \multirow[t]{3}{*}{ Tabel Pengadaan } & ID_Pengadaan \\
\hline & ID_Supplier \\
\hline & Tanggal Pengadaan \\
\hline \multirow[t]{3}{*}{ Tabel Detail Pengadaan } & ID_Pengadaan \\
\hline & ID_Produk \\
\hline & Jumlah \\
\hline \multirow[t]{5}{*}{ Tabel Persediaan } & ID_Persediaan \\
\hline & ID_Produk \\
\hline & ID_Pengadaan \\
\hline & Tanggal Stok Masuk \\
\hline & Jumlah \\
\hline \multirow[t]{9}{*}{ Tabel Persediaan Cabang } & ID_Persediaan Cabang \\
\hline & ID_Cabang \\
\hline & ID_Pengiriman \\
\hline & Nama Produk \\
\hline & Stok Awal \\
\hline & Tanggal Stok Awal \\
\hline & Jumlah Stok Awal \\
\hline & SK \\
\hline & SA \\
\hline
\end{tabular}


Tabel 1. TABEL EXTRACT [LANJUTAN]

\begin{tabular}{ll}
\hline \hline Nama Tabel & Field \\
\hline Tabel Pengiriman & ID_Pengiriman \\
\cline { 2 - 2 } & ID_Produk \\
\cline { 2 - 2 } & ID_Cabang \\
\hline Tanggal Pengiriman \\
\hline Tabel Detail Pengiriman & ID_Pengiriman \\
\cline { 2 - 2 } & ID_Persediaan \\
\hline Tabel Penjualan & Qty \\
\cline { 2 - 2 } & No_Invoice \\
\cline { 2 - 2 } & ID_Konsumen \\
\hline ID_Cabang \\
\cline { 2 - 2 } & Tanggal Penjualan \\
\hline Tabel Detail Penjualan & No_Invoice \\
\cline { 2 - 2 } & ID_Persediaan Cabang \\
\cline { 2 - 2 } & Nama Produk \\
\cline { 2 - 2 } & Qty \\
\hline
\end{tabular}

\section{B. Transform}

Proses ini data yang telah diambil pada proses extract akan dibersihkan dan mengubah data dari bentuk asli menjadi bentuk yang sesuai dengan kebutuhan data warehouse [11]. Proses transform yang dilakukan yaitu cleaning dan conditioning. Kedua proses ini menghasilkan tabel fakta dan dimensi yang terlibat pada pemodelan skema data warehouse. Tabel Fakta adalah tabel yang merepresentasikan pusat data dan Tabel Dimensi adalah tabel yang berisi nilai tersebut. Tabel Fakta yang dihasilkan pada proses ini terdapat pada Tabel 2 .

Tabel 2. TABEL FAKTA [LANJUTAN]

\begin{tabular}{ll}
\hline \hline Nama Tabel Fakta & Field \\
\hline Fact_Persediaan & ID_Persediaan \\
\cline { 2 - 2 } & ID_Produk \\
\cline { 2 - 2 } & ID_Pengadaan \\
\cline { 2 - 2 } Jumlah Stok Masuk \\
\cline { 2 - 2 } & SK \\
\hline Fact_Persediaan_cabang & SA_Persediaan Cabang \\
\cline { 2 - 2 } & ID_Cabang \\
\hline & ID_Pengiriman \\
\hline
\end{tabular}


INTENSIF, Vol.3 No.2 August 2019

ISSN: 2580-409X (Print) / 2549-6824 (Online)

DOI: https://doi.org/10.29407/intensif.v3i2.12769

Tabel 2. Tabel Fakta [lanjutan]

\begin{tabular}{ll}
\hline \hline Nama Tabel Fakta & Field \\
\hline & Nama Produk \\
\cline { 2 - 2 } & Stok Awal \\
\cline { 2 - 2 } & Jumlah Stok Awal \\
\cline { 2 - 2 } & SK \\
\hline Fact_detail_pengadaan & ID_Pengadaan \\
\hline & ID_Produk \\
\cline { 2 - 2 } & Jumlah \\
\hline Fact_detail_pengiriman & ID_Pengiriman \\
\cline { 2 - 2 } & ID_Persediaan \\
\cline { 2 - 2 } & Nama Produk \\
\cline { 2 - 2 } & Qty \\
\hline Fact_detail_penjualan & No_Invoice \\
\cline { 2 - 2 } & ID_Persediaan Cabang \\
\cline { 2 - 2 } & Nama Produk \\
\cline { 2 - 2 } & Qty \\
\hline
\end{tabular}

\section{Loading}

Proses loading dilakukan secara otomatis setelah proses transform selesai.

Setelah tahapan ETL selesai dilakukan maka akan dimodelkan sebuah skema data warehouse yang merupakan relasi antara tabel fakta dan tabel dimensi yang sudah dimodelkan sebelumnya. Tabel Fakta dan Tabel Dimensi yang digunakan untuk pemodelan data warehouse terdapat pada tabel 3.

Tabel 3. Tabel Fakta dan Dimensi untuk Pemodelan Data Warehouse [Lanjutan]

\begin{tabular}{lc}
\hline \hline Nama Tabel Fakta & Jenis Tabel \\
\hline Dim_Produk & Dimensi \\
\hline Dim_Cabang & Dimensi \\
\hline Dim_Konsumen & Dimensi \\
\hline Dim_Supplier & Dimensi \\
\hline Dim_Pengadaan & Dimensi \\
\hline Dim_Pengiriman & Dimensi \\
\hline Dim_Penjualan & Dimensi \\
\hline Dim_Tanggal_Pengadaan & Dimensi \\
\hline Dim_Tanggal_Pengiriman & Dimensi \\
\hline Dim_Tanggal_Penjualan & Dimensi \\
\hline
\end{tabular}


INTENSIF, Vol.3 No.2 August 2019

ISSN: 2580-409X (Print) / 2549-6824 (Online)

DOI: https://doi.org/10.29407/intensif.v3i2.12769

Tabel 3. Tabel FaKta dan Dimensi untuk Pemodelan Data Warehouse [LANJUTAN]

\begin{tabular}{lc}
\hline \hline Nama Tabel Fakta & Jenis Tabel \\
\hline Fact_persediaan & Fakta \\
\hline Fact_Persediaan_Cabang & Fakta \\
\hline Fact_Detail_Pengadaan & Fakta \\
\hline Fact_Detail_Pengiriman & Fakta \\
\hline Fact_Detail_Penjualan & Fakta \\
\hline
\end{tabular}

Dari hasil relasi antara tabel fakta dan tabel dimensi maka akan dimodelkan sebuah skema data warehouse yang akan menjadi wadah atau area data yang dibutuhkan oleh perusahaan sesuai dengan kebutuhan informasi strategis dalam hal distribusi produk. Model skema data warehouse yang terbentuk menggunakan pemodelan yang berjenis Snowflake Schema atau Skema Bola Salju. Pemodelan ini dipilih karena adanya beberapa tabel fakta yang berelasi dengan berbagai tabel dimensi ataupun sebaliknya. Skema data warehouse untuk distribusi produk di PT. X. Hasil akhir pemodelan data dapat dilihat pada gambar 2.

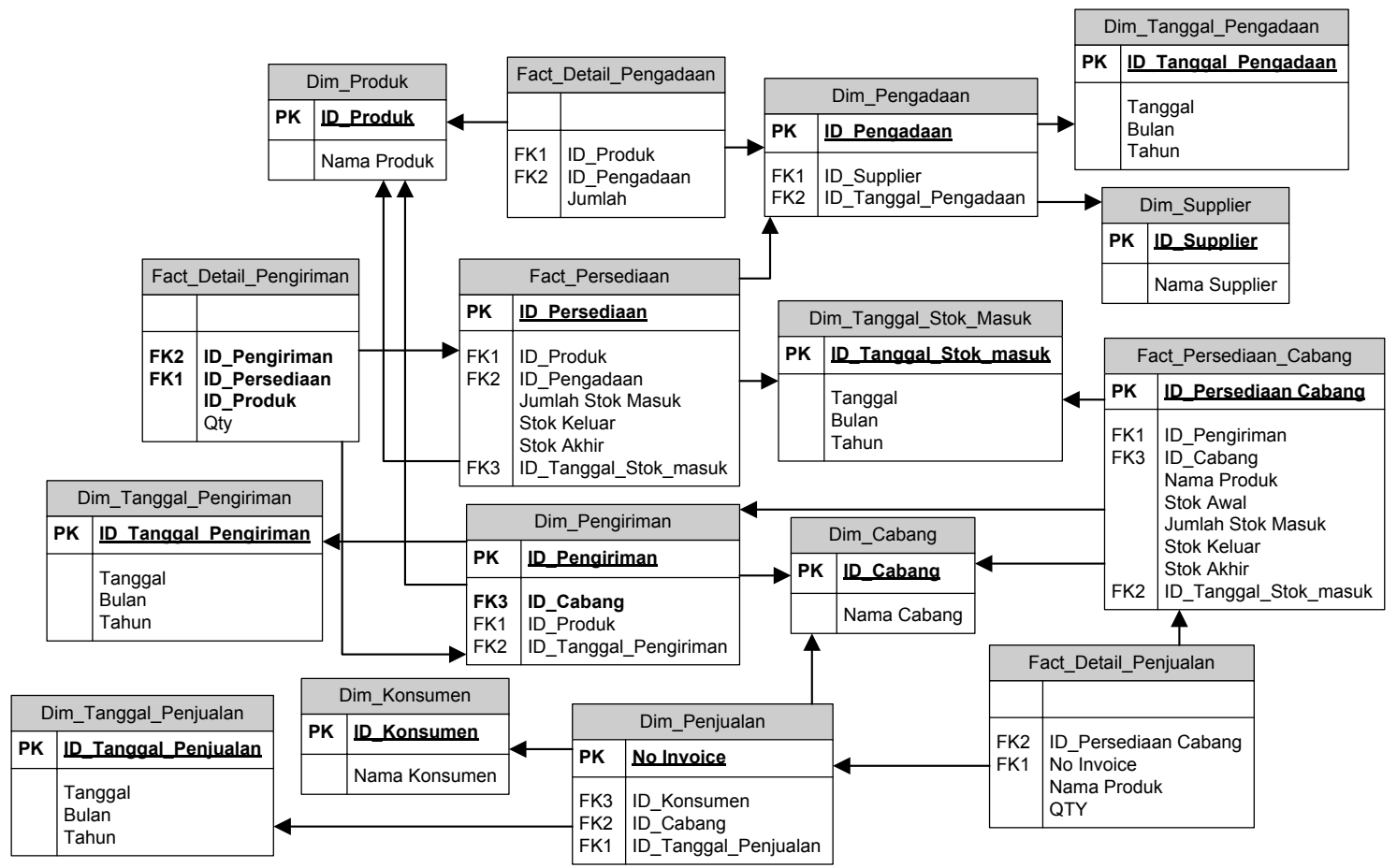

Gambar 2. Model SKema DATA WAREHOUSE UNTUK Distribusi PRODUK DI PT. X

INTENSIF: Jurnal Ilmiah Penelitian dan Penerapan Teknologi Sistem Informasi 
INTENSIF, Vol.3 No.2 August 2019

ISSN: 2580-409X (Print) / 2549-6824 (Online)

DOI: https://doi.org/10.29407/intensif.v3i2.12769

\section{KESIMPULAN DAN SARAN}

IBerdasarkan penelitian yang telah dilakukan maka dapat disimpulkan bahwa model data warehouse yang telah dibuat ini dapat menjadi acuan untuk menghasilkan informasi yang berguna bagi level manajerial PT. X khususnya pada proses distribusi produk. Model data warehouse ini akan menjadi wadah atau tempat untuk menampung seluruh data yang awalnya terpisah dan memiliki tipe yang berbeda sehingga perusahaan khususnya Kepala Distribusi mendapatkan kemudahan untuk mengelola data yang akan digunakan untuk distribusi produk. Selain itu, dengan model ini Kepada Distribusi akan mendapatkan kemudahan untuk mengakses data yang sesuai dengan kebutuhan informasi strategis perusahaan dan model yang dibangun dapat dijadikan acuan untuk menghasilkan informasi yang berguna bagi pihak manajerial PT. X pada penelitian selanjutnya

\section{UCAPAN TERIMAKASIH}

Terimakasih kepada Direktorat Riset dan Pengabdian Kepada Masyarakat, Direktorat Jenderal Penguatan Riset dan Pengembangan Kementerian Riset Teknologi dan Pendidikan Tinggi yang telah mendukung dan membiayai penelitian kami sehingga penelitian kami terselesaikan dengan baik

\section{DAFTAR PUSTAKA}

[1] R. Kimball, M. Ross, The Data Warehouse Toolkit: The Definitive Guide to Dimensional Modeling, Indianapolis: John Willey \& Sons, 2013.

[2] S. Darudiato, "Perancangan Data Warehouse Penjualan Untuk Mendukung Kebutuhan Informasi Eksekutif Cemerlang Skin Care," Seminar Nasional Informatika (SEMNASIF), vol. 1 No. 5, no. 350-359, 2010

[3] D. K. Widyawati, "Perancangan Struktur Data Warehouse untuk Mendukung Perencanaan Pemasaran Produk Menggunakan Star Schema," Jurnal Ilmiah ESAI, vol. 6 No. 3, 2012.

[4] J. Christian, "Model Data Warehouse Dengan Service Oriented Architecture Untuk Menunjang Sistem Informasi Eksekutif," Jurnal TELEMATIKA MKOM, vol. 2 No 2, pp. 103-115, 2010.

[5] D. J. Treiman, Quantitative Data Analysis: Doing Social Research to Test Ideas, John Wiley \& Sons, 2014.

[6] D. Dharmayanti, A. M. Bachtiar, A. Heryandi, "Pemodelan Data Warehouse pada Jurusan Teknik Informatika UNIKOM," Majalah Ilmiah Unikom, vol. 12 No. 2, pp. 151168, 2014.

[7] I. Indrajani, Database Design, Elex Media Komputindo, 2015.

[8] R. Thareja, Data Warehousing, Oxford Higher Education, 2009.

[9] M. Golfarelli, S. Rizzi, Data Warehouse Design : Modern Principles and Methodologies, Mc Graw Hill, 2010

[10] A. Supriyatna, M. Wahyudi, "Perancangan Data Warehouse Pada Perpustakaan Bina 
Sarana Informatika," Seminar Nasional Aplikasi Teknologi Informasi (SNATI), 2012.

[11] Softbless, "https://www.softbless.com/," PT. Softbless Solution, 2016. [Online]. Available: https://www.softbless.com/ETL-Indonesia. [Diakses:18-1-2019].

[12] F.Y. Al Irsyadi, "Implementasi Data Warehouse dan Data Mining Untuk Penentuan Rencana Strategis Penjualan Batik (Studi Kasus Batik Mahkota Laweyan)", KomuniTi, vol. VI, No. 1, pp. $42-58,2014$.

[13] A.R. Patel, "Data Modelling Techniques For Data Warehouse", ZENITH, International Journal of Multidiscilinary Research, Vol. 1 Issue 2, ISSN 2231 5780, pp. 240 - 246, 2012.

[14] F.W. Christanto, W.H. Utomo, E. Sediyono, "The Process of Data Tabulation Using Data Warehouse and OLAP Technology to Sales Analysis at Distributor Company", International Journal of Computer Science Issues (IJCSI), Vol. 9 Issue 3 No. 2, pp. 46 53, ISSN (Online) 1694-0814, 2012.

[15] S. Darudiato, "Perancangan Data Warehouse Penjualan Untuk Mendukung Kebutuhan Informasi Eksekutif Cemerlang Skin Care", Seminar Nasional Informatika 2010 (SemnasIF 2010) UPN “Veteran” Yogyakarta, pp. E-350 - E-359, ISSN 1979-2328, 2010.

[16] A. Dahlan, E. Utami, E.T. Luthfi, "Perancangan Data Warehouse Perpustakaan Perguruan Tinggi XYZ Menggunakan Metode Snowflake Schema", RESPATI, Jurnal Teknologi Informasi, Vol VIII No. 24, ISSN : 1907-2430, 2013. 